\title{
PEMODELAN SPEKTRUM SERAP DAN PANCAR ROTASI MOLEKUL UNTUK MENENTUKAN MOMEN INERSIA DAN MOMENTUM SUDUT ORBITAL
}

\author{
Ego Srivajawaty S, Hubertus Ngaderman
}

\author{
Fisika, MIPA, Universitas Cenderawasih, Waena, Jayapura, 99351, Indonesia \\ Universitas Cenderawasih, Waena, Jayapura, 99351, Indonesia \\ Email: srivajawati@ymail.com
}

\begin{abstract}
[Theory, computation and modeling] The purposes of this research are modeling rotation of the molecule, emiting or absorption energy. The parameters which involved for the rotation spectrum are molecular mass, inertia moment, quantum numbers and angular momentum orbital.

Made a pitch for a molecular spectrum rotation and inertia moment will be used methods from concept classical mechanics. Quantum mechanical used for determining angular momentum orbital. The spectral energy was counted for a molecular rotation $\mathrm{H}_{\mathrm{z}}$ and $\mathrm{NaCl}$ i.e $0,0152 \mathrm{eV}$ and $53,6 \times 10^{-\mathrm{e}} \mathrm{eV}$. Specific electromagnetics radiation for the energy absorption spectrum and emiting diatomic molecular at the moment that molecular vibrating were in the region spectrum infrared, whereas if the molecular rotated then its on the far infrared and microwave region.

Transition which emited measured up by selection rules that only commit for the quantum numbers $\mathrm{L}$ change as many as one unit, where identics with $\mathbb{I}$ as the quantum number for one atomic hidrogen. $\mathbb{L}$ was a quantum number take the values $0,1,2$, Transition which emited doesn't have all the same energy, but rather form a series energy which descend (or a series which go up wave length).
\end{abstract}

Keywords: rotation spectral diatomic (molecule); momen of inertia; angular momentum orbital

\section{PENDAHULUAN}

Spektrometer

(spektograph

atau spektroskopi) adalah sebuah instrumen optik yang digunakan untuk mengukur sifat cahaya yang merupakan bagian dari spektrum gelombang elektromagnetik. Analisis spektrokopis bertujuan untuk mengidentifikasi bahan-bahan dengan menggunakan spektrometer. Spektrometer diaplikasikan pada berbagai panjang gelombang dari sinar gamma sampai pada infamerah.

Spektroskopi atomik untuk mencirikan berbagai atom dari spektrum pancar dan serapnya, spektroskopi molekuler memungkinkan pencirian berbagai molekul. Setiap molekul memiliki ciri khas sidik jarinya sendiri yang mudah dikenal. Spektroskopi molekuler memberitahukan kita mengenai komposisi molekul - jumlah atom dari setiap jenis, perbandingan isotopik, bahkan pula keadaan ionisasi molekul, jadi kita dapat membedakan molekul $\mathrm{CO}$ dari $\mathrm{CO}_{z}, \mathrm{H}^{x s} \mathrm{Cl}$ dari $\mathrm{H}^{\mathrm{s}} \mathrm{Cl}, \mathrm{H}_{2}{ }^{*}$ dari $\mathrm{H}_{2}$. Dua penerapannya adalah dapat digunakan untuk mencirikan jumlah berbagai pencemar, sehingga dapat membantu kita mengukur kemurnian udara dan spektra serap dari debu antarbintang digunakan untuk mencirikan molekul-molekul kompleks dalam galaksi kita. Apabila ia diarahkan ke Bumi, maka ia dapat mengukur bagaimana radiasi inframerah yang dipancarkan diserap dalam atmosfer. Analisis teoritis untuk mendapatkan spektra rotasi dwiatom molekul. Konsep yang digunakan: konsep klasik dan konsep modern yaitu dengan melibatkan mekanika kuantum didalam menghitung momentum sudut orbital. Momen inersia molekul menggunakan klasik karena dianggap molekul masih berperan sebagai partikel klasik. Spektra rotasi molekul terhitung dan tidak muncul sebagai spektrum energi yang tampak didalam spektrometer, sebab tidak dilakukan eksperimen. Nilai spektra tersebut diperoleh lewat komputasi dengan menggunakan beberapa parameter yaitu massa molekul, momen inersia, bilangan kuantum dan momentum sudut orbital. Nilai parameterparameter tersebut yang akan digunakan untuk menghitung spektra energi rotasi molekul. Penulis melakukan penelitian tentang spektrofotometri vibrasi molekul dan tidak 
melakukan eksperimen untuk mengukur spektrum pancar dan serap seperti didalam mekanisme spektroskopi. Tujuan penelitian ini adalah pemodelan rotasi molekul, spektra energi serap dan pancar. Manfaat utama dari hasil penelitian ini antara lain adalah pemahaman yang baik tentang konsep struktur molekul didalam pengembangan yang lebih komprehensif mengenai spektroskopi molekuler.

Metode konsep dengan menghadirkan konsep mekanika klasik untuk membahas momen inersia dan mekanika kuantum untuk membahas momentum sudut orbital.

\section{METODOLOGI PENELITIAN}

Untuk mendapatkan momen inersia maka ditinjau dinamika rotasi, torka dan inersia rotasi partikel. Besaran $m r^{2}$ menyatakan inersia rotasi partikel yang disebut momen inersia.

$$
r=\sum m r^{2}
$$

Energi sistem atom hidrogen:

$$
E=H=\frac{p^{2}}{2 m}-\frac{q^{2}}{4 \pi \varepsilon_{0} r^{r}} .
$$

Persamaan Schrodinger dalam koordinat bola.

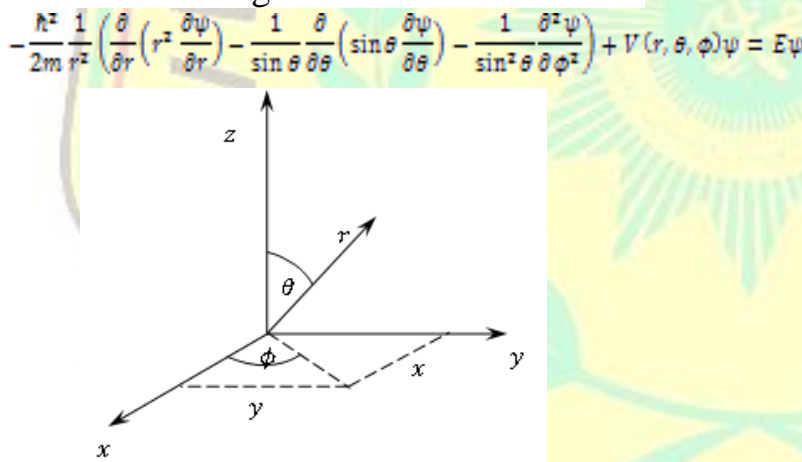

Gambar 1. Sistem koordinat bola $\left(r r_{x} \theta_{\alpha} \phi\right)$, yang lebih memadai ketimbang sistem $\left.\left[x_{0}, y_{i}\right]\right)$.

dimana $\psi=\psi\left(r_{i}, \theta, \phi\right)$. Pemecahannya terpisahkan sebagai

$$
\psi(r, \theta, \phi)=R(r) \theta(\theta) \Phi(\phi) .
$$

Penjumlahan akan sama dengan nol untuk sembarang nilai $r_{\imath} \theta$ dan $\phi$ jika masing-masing suku sama dengan konstanta.

$$
\frac{1}{R} \frac{d}{d r}\left(r^{2} \frac{d R}{d r}\right)+\frac{2 m r^{2}}{\hbar^{2}} E=I(I+1)
$$

Jika partikel bermassa $m$ bergerak dengan $r$ yang konstan maka

$$
\frac{1}{R} \frac{d}{d r}\left(r^{2} \frac{d R}{d r}\right)=0
$$

$$
\frac{2 m r^{2}}{h^{2}} E=I(I+1)
$$

dan

$$
p^{2}=\frac{l(I+1) k^{2}}{r^{2}}
$$

Momentum gerak linear partikel:

$$
p=\frac{\sqrt{l(I+1)} h}{r}
$$

Momentum sudut orbital

$$
\overrightarrow{\mathrm{L}}=\overrightarrow{\vec{r}} \times \vec{p}
$$

Maka

$$
L=\sqrt{L(I+1)} h .
$$

\section{HASIL DAN PEMBAHASAN}

Molekul dapat mengubah keadaan geraknya apabila ia menyerap atau memancarkan radiasi dengan berotasi mengelilingi pusat massanya.

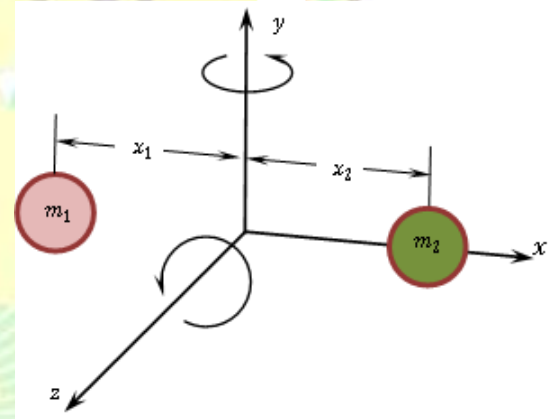

Gambar 2. Sebuah molekul diatomik yang berotasi.

Energi kinetik rotasi

$$
E_{K}=\frac{1}{2} I \omega^{2}
$$

$I$ momen lembam molekul dan $\omega$ kecepatan sudut. Energi kinetik ditulis dalam momentum sudut $|\vec{Z}|=I \omega$

$$
E_{K}=\frac{|\vec{L}|^{2 I}}{2 I}
$$

Momen lembam

$$
I=m_{1} x_{1}^{2}+m_{2} x_{2}^{2}
$$

Massa reduksi

$$
\mu=\frac{m_{1} m_{2}}{\left(m_{1}+m_{2}\right)}
$$

Terpisah dengan jarak setimbang $R=x_{1}+x_{2}$ sebagai

$$
I=\mu R^{2}
$$

$\mu$ digantikan menjadi $m$. Momentum sudut $\vec{I}$

$$
|\vec{I}|=\sqrt{l(l+1)} h
$$

$l=0,1,2,3, \ldots$

Energi dari molekul diatomik yang berotasi

$$
E=\frac{L(L+1) \hbar^{2}}{2 m R^{2}}
$$

kita mendapat 
$L$ suatu bilangan kuantum yang mengambil nilai $0,1_{2} 2_{s} \ldots$. Bila kita mengeksitasikan molekul ke suatu tingkat rotasi tinggi, ia akan turun kembali ke keadaan dasarnya dengan memancarkan foton-foton yang berkaitan dengan transisi rotasi yang bersangkutan. Aturan seleksi bagi fotonfoton ini adalah

$$
|\Delta L|=1
$$

Energi foton

$$
\begin{aligned}
\Delta E & =E_{L+1}-E_{L} \\
& =(L+1) \frac{\hbar^{2}}{m R^{2}}
\end{aligned}
$$

Energi transisi rotasi bergantung pada $\bar{L}$.

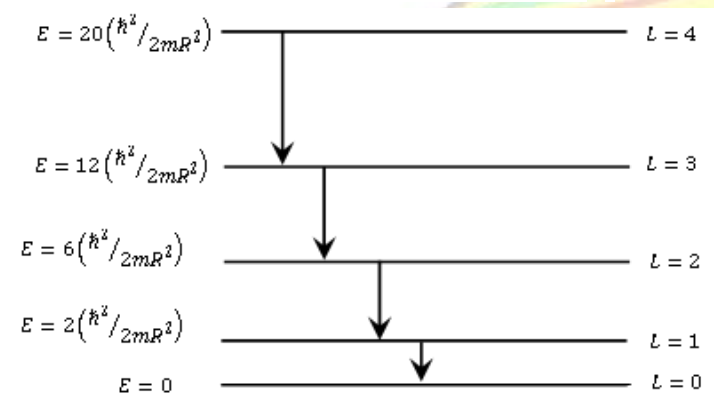

Energi foton bergantung pada besaran ${ }^{2} / h_{m R^{2}}$, energi bagi $\mathrm{H}_{2}$ :

$$
\frac{\hbar^{2}}{m R^{2}}=0,0152 \mathrm{eV}
$$

Transisi rotasi dalam hidrogen memiliki energi dan panjang gelombang berikut:

$$
\begin{array}{lll}
L=1 \text { ke } L=0 & \Delta E=0,0152 \mathrm{eV} & \lambda=81,6 \mathrm{~mm} \\
L=2 \operatorname{ke} L=1 & \Delta E=0,0304 \mathrm{eV} & \lambda=40,8 \mu \mathrm{m} \\
L=3 \text { ke } L=2 & \Delta E=0,0456 \mathrm{eV} & \lambda=27,2 \mu \mathrm{m}
\end{array}
$$

Energi yang dipancarkan membentuk deret $\Delta E_{v} 2 \Delta E_{v} 3 \Delta E_{v} \ldots$, dan begitu pula panjang gelombang yang dipancarkan $\lambda_{x} \lambda / 2, \lambda / 3, \ldots$ Panjang gelombangnya dalam daerah "inframerah jauh" (far infrared). Bagi NaCl,

$$
\frac{\hbar^{2}}{m R^{2}}=53,6 \times 10^{-6} \mathrm{eV}
$$

Tiga transisi pertamanya

$L=1 \mathrm{ke} L=0 \quad \Delta E=53,6 \times 10^{-\mathrm{s}} \mathrm{eV} \quad \lambda=23,1 \mathrm{~mm}$

$L=2 \mathrm{ke} L=1 \quad \Delta E=107_{2} 2 \times 10^{-\mathrm{s}} \mathrm{eV} \quad \lambda=11_{2} 6 \mathrm{~mm}$
$L=3 \mathrm{ke} L=2 \quad \Delta E=160 \times 10^{-\mathrm{s}} \mathrm{eV} \quad \lambda=7,71 \mathrm{~mm}$

Semua transisi berada dalam daerah gelombang mikro.

\section{KESIMPULAN}

Tingkat-tingkat energi rotasi 10 hingga 100 kali lebih rapat daripada tingkat-tingkat energi vibrasi, dengan transisinya berada dalam daerah inframerah jauh dan gelombang mikro. Transisi yang dipancarkan tidak semuanya memiliki energi yang sama, melainkan merupakan suatu deret energi yang menurun (atau suatu deret panjang gelombang yang naik). Transisi yang dipancarkan dibatasi oleh aturan seleksi yang memperkenankan bilangan kuantum $L$ berubah sebanyak satu unit.

Riset ini untuk molekul $\mathrm{H}_{2}$ dan $\mathrm{NaCl}$, perlu diadakan penelitian lain untuk molekul-molekul lainnya. Perlu diadakan riset teoritis yang melibatkan mekanika kuantum untuk mendapatkan momen inersia.

\section{DAFTAR PUSTAKA}

Barrow G, Introduction to Molecular Spectroscopy. New York, McGrawHill, 1962).

Griffiths J D, 1994 , Introduction to Quantum Mechanics. Prentice Hall, New Jersey.

Halliday D, Resnick R dan Walker J, Fisika Jilid Dua Versi Diperluas. Binarupa Aksara.

Halliday, 1986, Fisika Jilid Satu. Airlangga.

Halliday, 1986, Fisika Jilid Dua. Airlangga.

Krane Keneth S, 1992. Fisika Modern. John Wiley and Sons.

Ngaderman H, 2014, Tinjauan Konseptual Vibrasi Molekul dan Mekanika Klasik untuk Spektrofotometri Molekuler. Universitas Cenderawasih.

Pauling L, 1935, Introduction to Quantum Mechanics. McGraw-Hill Company, INC. 